\title{
Large Asian dust layers continuously reached North America in April 2010
}

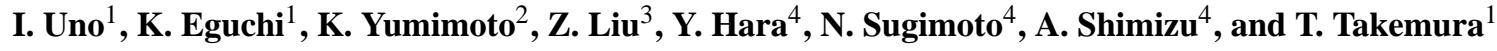 \\ ${ }^{1}$ Research Institute for Applied Mechanics, Kyushu University, Kasuga, Fukuoka, Japan \\ ${ }^{2}$ Meteorological Research Institute, Tsukuba, Japan \\ ${ }^{3}$ National Institute of Aerospace, Hampton, Virginia, USA \\ ${ }^{4}$ National Institute for Environmental Studies, Tsukuba, Japan
}

Received: 1 February 2011 - Published in Atmos. Chem. Phys. Discuss.: 19 April 2011

Revised: 16 July 2011 - Accepted: 20 July 2011 - Published: 25 July 2011

\begin{abstract}
The NASA space-borne Mie-lidar system CALIPSO/CALIOP revealed that multiple large Asian dust layers with a horizontal scale of $2000-3000 \mathrm{~km}$ reached North America, occupying the full troposphere, in April 2010. This kind of dust layer transport has not been reported before. Our analysis of CALIOP data and global aerosol model results revealed that frequent dust emissions occurred in northwestern China because of stronger-thanaverage near-surface winds, and that strong stable westerly winds carried the Asian dust from northwestern China to the central Pacific Ocean. A negative pressure anomaly was located in the eastern Pacific Ocean, and the main dust transport path was split into two branches: a northern path and a southern path over North America. Northern-path dust was trapped and stagnant for a longer time than southern path dust and finally subsided under a high-pressure system. Dust along the southern path reached the central US. These complex conditions resulted in a multi-layered structure of dust over North America.
\end{abstract}

\section{Introduction}

Long-range transport of Asian dust appears in the upper troposphere on a trans-Pacific scale almost every spring (e.g., Huser et al., 2001; Eguchi et al., 2009). This phenomenon occurs approximately two to three times each spring (e.g., VanCuren and Cahill, 2002), usually as a horizontally stretched thin single dust layer over the west coast of

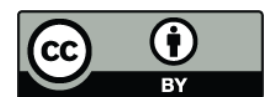

Correspondence to: I. Uno (uno@ riam.kyushu-u.ac.jp) mid-latitude North America (Yumimoto et al., 2009). However, in the spring of 2010, a NASA space-borne Mie-lidar system (CALIPSO/CALIOP) observed multiple Asian dust layers that arrived over the US and maintained an average width of more than $2000 \mathrm{~km}$ and an average height of $10 \mathrm{~km}$ as they traveled across the Earth. Trajectory analyses revealed that the dust originated in China's Taklimakan and Gobi deserts. CALIPSO measurements clearly captured the dust moving across the Pacific Ocean, through the United States and Canada, and over Virginia (NASA web site: http: //www.nasa.gov/topics/earth/features/dustcloud.html).

To the best of our knowledge, this is the first time that the transport of such thick and large multiple dust layers has been observed in trans-Pacific dust transport analysis. This paper discusses several key aspects of this extreme episode. First, how were such spatially extensive dust layers efficiently transported and maintained over North America? Second, why did this "extreme dust event" appear only in 2010? This study sought to answer these questions and investigated the relationships between the anomalous extreme meteorological conditions in 2010 and dust emission/transport patterns.

\section{Observation data and dust transport model}

The Cloud-Aerosol Lidar with Orthogonal Polarization (CALIOP) instrument was launched on board the CloudAerosol Lidar and Infrared Pathfinder Satellite Observation (CALIPSO) satellite in April 2006. Since then, it has provided continuous global measurements of aerosol and cloud vertical distributions with high spatial resolution (Winker et al., 2007, 2010). CALIOP is a two-wavelength (532 and $1064 \mathrm{~nm}$ ) backscatter lidar that can measure two orthogonal polarization components at $532 \mathrm{~nm}$, with sampling at $333 \mathrm{~nm}$

Published by Copernicus Publications on behalf of the European Geosciences Union. 
along the track. In this study, we used Level 1B CALIOP data (version 3.01), i.e., the total attenuated backscatter and the volume depolarization ratio $(\delta)$, both at $532 \mathrm{~nm}$. We derived the aerosol extinction coefficient using the Fernald inversion technique by setting the lidar ratio, S1, at $35 \mathrm{sr}$ (Shimizu et al., 2004). The inversion starting height was set at $14 \mathrm{~km}$ assuming that the background aerosol concentration at this height could be ignored and that this height layer does not include the main part of the stratosphere. Inversion progressed down to the ground surface, and the dust fraction was then calculated using $\delta$ information. The retrieved vertical profiles were averaged to a horizontal resolution of $5 \mathrm{~km}$. The cloud-aerosol discriminator (CAD) index from Level 2 CALIOP data was used to detect cloud layers; we analyzed only nighttime observation data because of the high signal-to-noise ratio (SNR). Detailed descriptions can be found on the CALIPSO mission webpage (http: //www-calipso.larc.nasa.gov/) and in the references provided there. Uno et al. $(2008,2009)$ have published detailed descriptions of our data analysis methods. Note that the S1 value of $35 \mathrm{sr}$ applied in the CALIOP extinction retrieval was smaller than the value of $50 \mathrm{sr}$ used in the National Institute of Environmental Studies (NIES) ground-based lidar network measurements. This smaller value was applied to obtain the overall semi-quantitative aerosol profile. As a result, the extinction coefficient retrieved from the CALIOP measurement may be smaller than that from the NIES measurements by a factor of $\sim 0.6(=30 / 50)$ for optically thinner cases. Fixed S1 might produce over-decay within the cloud layer (where S1 is around 20), leading to overestimation of aerosol under that cloud. However, this is not critical in the present study because our main focus is semiquantitative analysis of the dust transport (i.e., a comparison of dust vertical structure and horizontal scale) using the CALIOP measurement.

The CloudSAT satellite was launched together with CALIPSO to collect cloud and precipitation data. The Cloud Profiling Radar (CPR) onboard CloudSAT is a 94$\mathrm{GHz}$ nadir-looking radar that measures the backscatter from clouds as a function of the distance from the radar. CPR can measure clouds and precipitation consisting of large droplets. Therefore, this study used CPR data to identify dense clouds, which cannot be fully penetrated and measured at the CALIOP (visible and near infrared) wavelengths.

We used the global Spectral Radiation-Transport Model for Aerosol Species (SPRINTARS, Takemura et al., 2005) to simulate long-range dust transport on an Asia-Pacific OceanNorth Atlantic Ocean scale. The horizontal resolution was set to T106 (about $1.125^{\circ}$ ), with 56 vertical layers in a sigma coordinate. SPRINTARS was nudged by National Centers for Environmental Prediction (NCEP) reanalysis data $\left(2.5^{\circ} \times 2.5^{\circ}, \mathrm{http}: / / \mathrm{dss} . u c a r . e d u /\right.$ datasets/ds090.0/). The soil moisture condition is sensitive to dust emission; in this study, we nudged the soil wetness to NOAA monthly mean soil moisture data (Van den Dool et al., 2003) to incorporate ob-
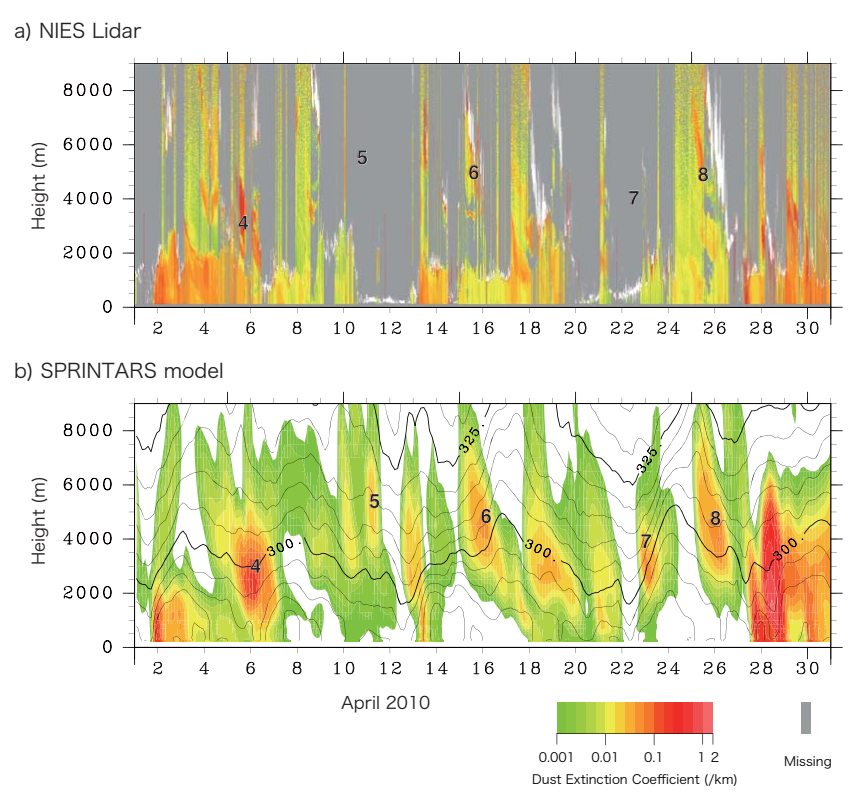

Fig. 1. Time-height cross-section of the dust extinction coefficient at Matsue (35.3 $\left.{ }^{\circ} \mathrm{N}, 132.7^{\circ} \mathrm{E}\right)$, Japan, in April 2010. (a) NIES lidar observation, (b) SPRINTARS simulation with potential temperature (contour). Numbers show the model-identified dust episode (shown in Fig. 4).

servation data. From 1 March to 30 April, simulated dust emission flux revealed approximately eight dust episodes (see Fig. 4 for daily averaged dust emissions). To track dust transport from specified dust episodes, we also conducted several sensitivity analyses of SPRINTARS by controlling the dust emission (i.e., all dust sources, only Asian dust sources, and dust sources by emission period).

As a reference, we used the dataset acquired by the NIES lidar network (http://www-lidar.nies.go.jp/), a ground-based lidar network over Asia. This network consists of 22 observation sites distributed over Japan, Korea, China, Mongolia, and Thailand and provides continuous measurements of vertical profiles of aerosols (Shimizu et al., 2004). We examined several Japanese lidar sites to assess the frequency of typical dust events, especially cases of highly elevated dust layers. Our analysis confirmed at least eight elevated dust layers (heights $2000-5000 \mathrm{~m})$ at the Matsue site in Japan $\left(35.3^{\circ} \mathrm{N}\right.$, $132.7^{\circ} \mathrm{E}$ ), which agreed well with the modeled results. Figure 1 presents a time-height plot of the dust extinction coefficient based on lidar measurements and numerical model results. Numbers in Fig. 1 show the model-identified dust episode (shown in Fig. 4) and the NIES lidar-observed elevated dust layer very clearly when there is no cloud. 

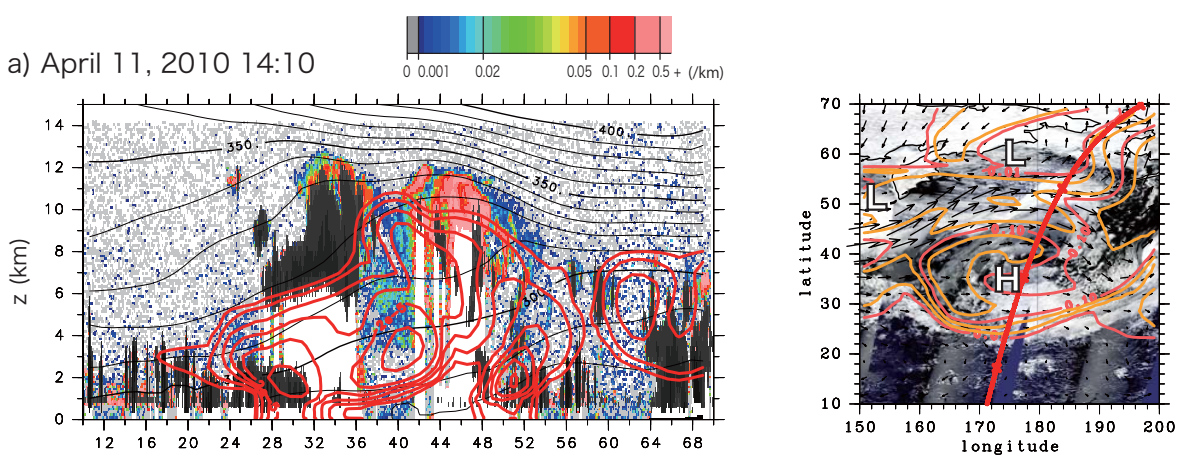

b) April 15, $201010: 28$
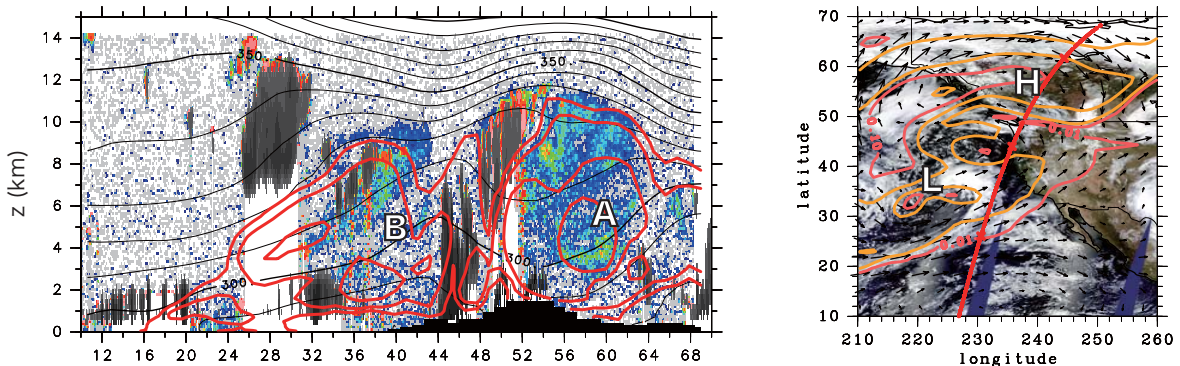

c) April 17, $201008: 37$
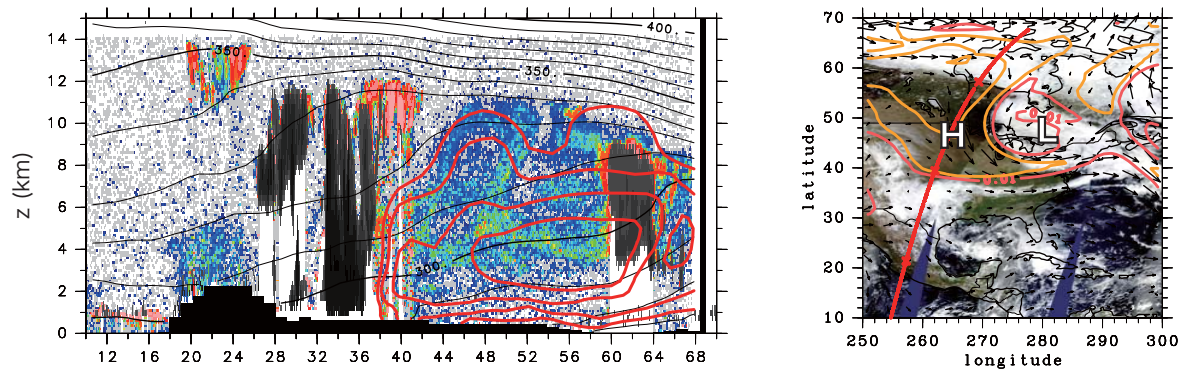

d) April 22, 2010 07:17
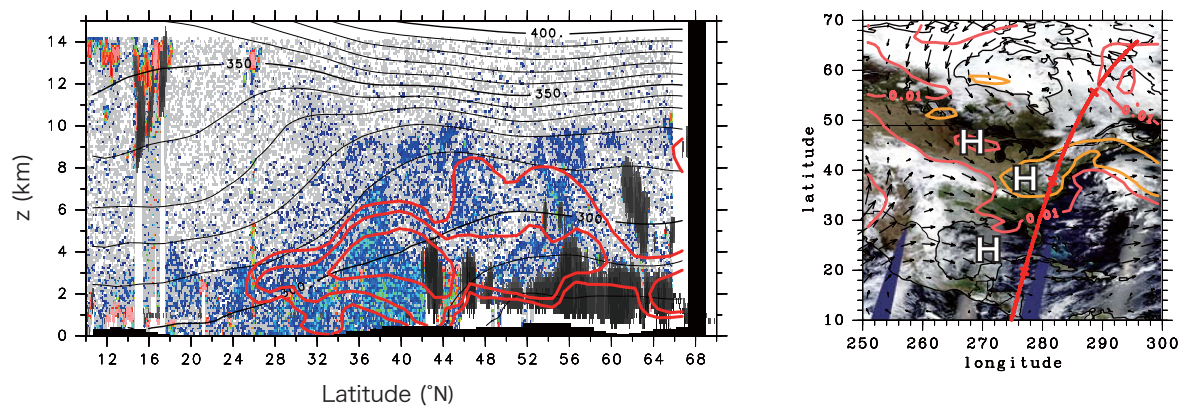

Fig. 2. (Left column) Snapshot of dust extinction coefficient cross-section observed by CALIOP (color), CloudSat CPR echo intensity (black/white), and simulated by SPRINTARS (red). The black line indicates potential temperatures. (Right column) CALIPSO path, SPRINTARS dust AOT distribution, and MODIS cloud image. (a) 11 April, (b) 15 April, (c) 17 April, and (d) 22 April.

\section{Results and discussion}

\subsection{Observed structure of large asian dust layers}

Figure 2 presents four snapshots of Asian dust extinction coefficient cross-sections (curtain-plot) observed by CALIOP (color) and simulated by SPRINTARS (red contour), and cloud echo intensity by CloudSat CPR (black/white). White areas indicate that CALIOP data inversion was unsuccessful due to cloud cover. The figure includes the potential temperatures (black contour) from the model. The right column shows the CALIPSO path and SPRINTARS dust AOT distribution with the wind field at $500 \mathrm{hPa}$ overlain on the MODIS red, green, blue image. Figure 3 a shows the CALIPSO orbit 
a)

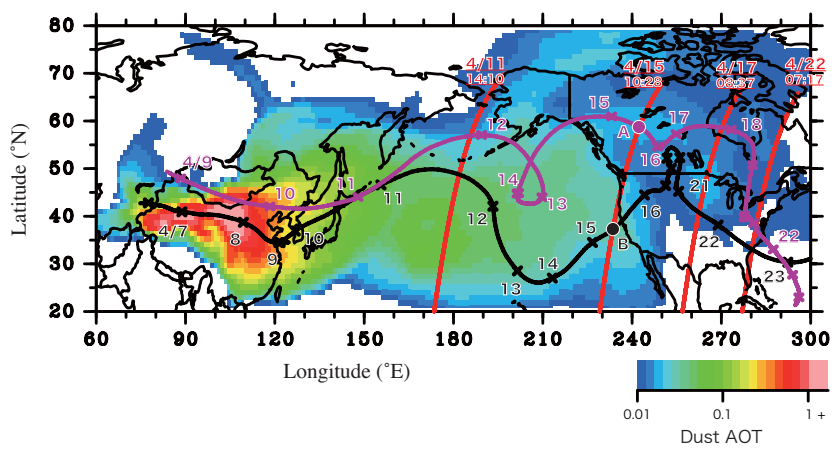

b)

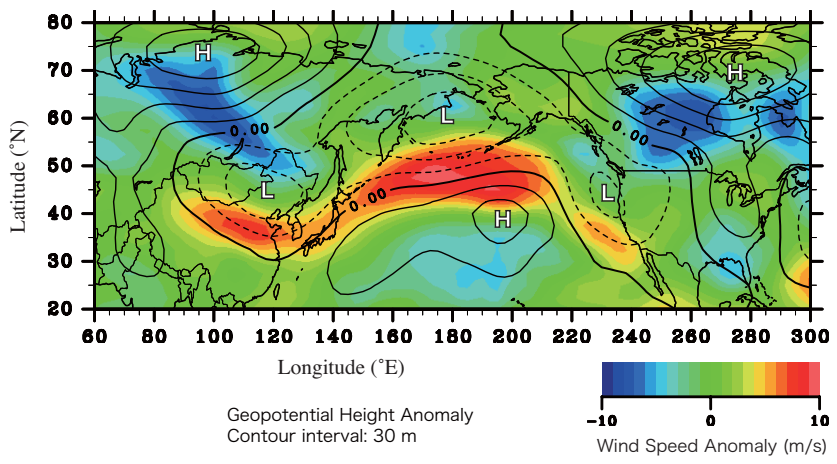

Fig. 3. (a) Averaged dust AOT (color) and two HYSPLIT trajectories (black A and pink B) beginning at CALIPSO orbit points (15 April). Red lines indicate CALIPSO orbit paths. Numbers on trajectories show the date in April 2010. (b) Anomaly in $500-\mathrm{hPa}$ geopotential height (contour) and wind speed (color) in April at $500 \mathrm{hPa}$.

path for the same four cases and the averaged dust AOT (logscale) distribution based on the SPRINTARS model. The figure also shows two trajectory lines (A, B) starting from the CALIPSO heavy dust observation points (see Fig. 2b). These four snapshots were selected to show the horizontal/vertical scale of the Asian dust, and observation times roughly coincide with the crossing time of trajectories A and B.

Figure 2a shows the dust distribution over the central $\mathrm{Pa}$ cific Ocean on 11 April. Thick high cloud $\left(28^{\circ} \mathrm{N}-36^{\circ} \mathrm{N}\right)$ appeared within the high-pressure circulation region. A thin low cloud layer just south of the tall cloud extended from the ocean surface to a height of $1-2 \mathrm{~km}$. CALIOP observed strong backscatter at heights around 10-12 km $\left(42^{\circ} \mathrm{N}-48^{\circ} \mathrm{N}\right)$, and CAD information indicated a cloud layer. We were unable to make a reliable inversion below this altitude. The CloudSat CPR did not detect a thick cloud signal there. This indicates the presence at this height of optically thick cirrus cloud composed of small ice particles.

Most of the dust layer was located at latitudes between $28^{\circ} \mathrm{N}$ and $52^{\circ} \mathrm{N}$ within the cloud-free zone. Because of the tall cloud, CALIOP was unable to detect the entire dust structure. However, our model was able to simulate and portray the detailed dust structure. This is a great advantage of integrated analysis that combines model simulations and observations (Uno et al., 2008). The horizontal scale of the dust plume exceeded $2500 \mathrm{~km}$, and its vertical height scale was already scattered to a large extent $(1-8 \mathrm{~km})$ over the central Pacific Ocean.

Figure $2 \mathrm{~b}$ shows the dust distribution over the eastern $\mathrm{Pa}$ cific, San Francisco area, and Canada on 15 April. Meteorological analysis and MODIS cloud images indicate a cold (warm) front located at latitudes around $32-36^{\circ} \mathrm{N}(48$ $50^{\circ} \mathrm{N}$ ) along the CALIPSO orbit path. The AOT distribution shows two separate dust layers. We can see two dust cores. One (B) was located between $26-44^{\circ} \mathrm{N}$ within the warm sector and vertically at $4-8 \mathrm{~km}$, tilting upward to the north (parallel to a potential temperature of $300 \mathrm{~K}$ ). The other (A) was located within a high-pressure system at $52-65^{\circ} \mathrm{N}$ with heights extended further from $2-10 \mathrm{~km}$.

Figure $2 \mathrm{c}$ shows the dust distribution over the central United States to Canada on 17 April. This large, thick dust layer (at $40-62^{\circ} \mathrm{N}$ with heights ranging from $2-10 \mathrm{~km}$ ) was mainly stagnant within a large high-pressure system and correlated with dust cloud A shown in Fig. 2b (also see the trajectory analysis in Fig. 3a).

Figure $2 \mathrm{~d}$ shows the dust distribution over the eastern United States on 22 April. A thick dust layer appeared at $32-44^{\circ} \mathrm{N}$ with heights ranging from near the surface to $3 \mathrm{~km}$. Trajectory A analysis indicated that the air mass descended 2500-3000 m between 18 and 23 April due to subsidence under a large high-pressure system. The trajectory analysis indicated that the four selected snapshots from CALIOP measurements appropriately tracked dust core A (see A in Figs. 2b-d).

Figure 2 indicates that the horizontal scale of the dust exceeded $2000 \mathrm{~km}$ and ranged vertically from 1-10 km (sometimes with a multi-layered structure). These complex structures had already formed over the northwestern Pacific Ocean. Multiple Asian dust layers have also been reported by $\mathrm{Su}$ and Toon (2011). Dust snapshot analysis revealed that most dust plumes had potential temperatures of 290 $310 \mathrm{~K}$. Meteorological data analysis showed a large highpressure system traveling within North America very slowly over 7 days (15-22 April), trapping the large Asian dust layer. These characteristics of the observed dust layer were explained well by the model.

\subsection{Average dust AOT field and air flow anomaly}

To understand the airflow patterns that were associated with the dust transport in 2010 we examined geopotential height anomalies at $500 \mathrm{hPa}$. Figure $3 \mathrm{~b}$ presents anomalies at $500 \mathrm{hPa}$ geopotential height (contour) and wind speed (color) in April 2010 from the 30-year NCEP/National Center for Atmospheric Research (NCAR) reanalysis mean field (1981-2010). Liang et al. (2005) examined long-range transport of Asian pollution outflows using the GEOS-Chem 
model and found that trans-Pacific transport is characterized by strong zonal winds associated with a high-pressure system over the northwestern Pacific (Pacific High) and a deep low over Alaska and the Aleutian Islands (Aleutian Low). The pattern shown in Fig. 3 is consistent with these findings, indicating that the pressure field during the dust event favored efficient trans-Pacific transport.

We found that the westerly was quite stable from western China to central Pacific Ocean (air flow was nearly parallel to the geopotential height anomaly at a $0 \mathrm{~m}$ height level), and the average westerly at $500 \mathrm{hPa}$ in April 2010 was approximately $50 \%$ stronger than the 30 -year average around northwestern China and the central Pacific Ocean.

We also examined the MODIS Deep Blue AOT (Hsu et al., 2006) and wind speed distribution surrounding the Taklimakan Desert. We set a rectangular evaluation region of $75-90^{\circ} \mathrm{E}, 35-42^{\circ} \mathrm{N}$. The average Deep Blue AOT in MarchApril from 2005-2010 (we excluded data from 2007 because this year was particularly dusty) was 0.85 , and the 2010 value was $14 \%$ larger than this average. NCEP reanalysis of wind speeds at sigma $=0.995$ (near surface height) revealed that the 30-year average for April was $6.2 \mathrm{~m} \mathrm{~s}^{-1}$ while the annual mean for 2010 was $6.4 \mathrm{~m} \mathrm{~s}^{-1}$. Significant differences appeared in strong wind frequency: the frequency of wind exceeding $7 \mathrm{~m} \mathrm{~s}^{-1}$ in $2010(36 \%)$ was $33 \%$ greater than the 30 -year average $(27 \%)$. Close correlation has been found between Arctic oscillation (AO) and dust storm frequency in northern China during spring (Gong et al., 2006; Mao et al., 2011). When AO is in a negative phase, colder surface temperatures, strong weather variances, and more frequent cold surges are known to occur over northern China (e.g., Mao et al., 2011). The intensity of AO during winter-spring 2010 underwent a largely negative phase (see http://www.cpc.noaa.gov/products/precip/ CWlink/daily_ao_index/ao_index.html). The strong negative phase of $\mathrm{AO}$ is one reason for the higher frequency of strong winds, which was a favorable condition for the frequent dust emissions in 2010.

A low-pressure anomaly appeared over the eastern North Pacific and a high-pressure anomaly appeared over northern U.S. regions. The low-pressure anomaly tended to split the airflow into northern and southern branches over the eastern North Pacific. This flow pattern explains the observed phenomena that the trans-Pacific-scale Asian dust plume had two branches after reaching the eastern North Pacific: one towards the western US-northern Canada-central/eastern US and the other towards the western-central/southern-eastern US Examples of these branches are shown by trajectories A and B in Fig. 3a.

\subsection{Trans-pacific transport of asian dust in April 2010}

As described in Sect. 2, at least eight large dust emission events were simulated for the inland desert area of China, and these frequent dust episodes helped generate the large
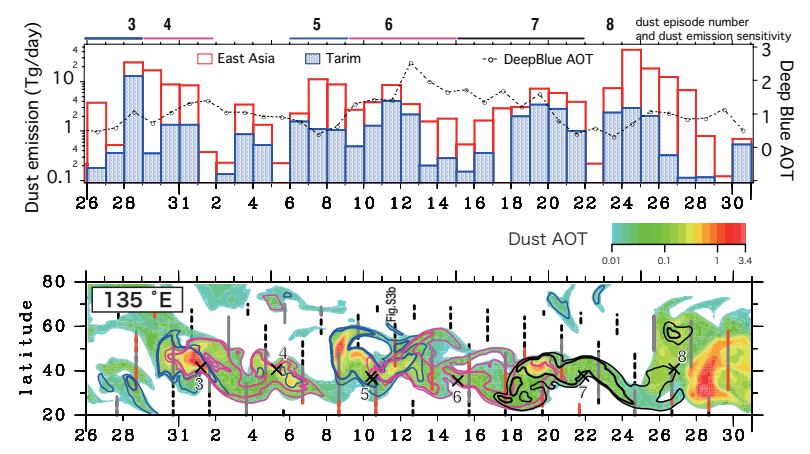

c)

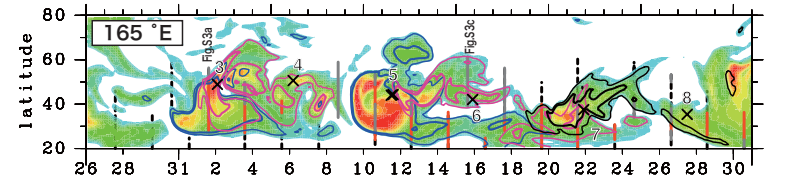

d)
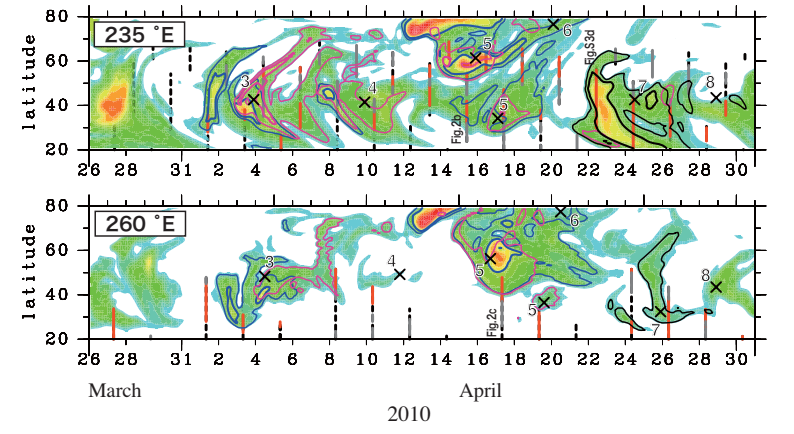

Fig. 4. (a) Daily dust emission flux (bar) over the Asia domain and MODIS Deep Blue AOT (dotted line), (b-e) Daily changes in dust AOT (color) at $135^{\circ} \mathrm{E}, 165^{\circ} \mathrm{E}, 235^{\circ} \mathrm{E}$, and $260^{\circ} \mathrm{E}$ between 26 March and 30 April. Straight red bars indicate that dust layers were observed by CALIOP. Broken lines and gray bars indicate non-dust and cloud layers, respectively. Contours are AOT from the dust sensitivity experiment for dust episodes 3-7.

dust layers observed over North America. To investigate the details of dust transport during these episodes, we selected several meridian sections to show the variation and transport of Asian dust.

Figure 4a shows modeled daily dust emission flux and Deep Blue AOT for the dust source region; Fig. 4b-f show daily changes in dust $\mathrm{AOT}$ at $135^{\circ} \mathrm{E}, 165^{\circ} \mathrm{E}, 235^{\circ} \mathrm{E}$, and $260^{\circ} \mathrm{E}$ from 26 March-30 April. The major dust emission events are numbered in these figures. A HYSPLIT trajectory analysis (Draxler and Rolph, 2010) was conducted to determine the crossing time at each meridian. Corresponding dust event numbers are also shown for each section. Vertical bars indicate the CALIOP measurement within \pm 5 degrees of the specified meridian. Straight red bars indicate that dust layers were observed by CALIOP during that day. Broken lines and gray bars denote non-dust and cloud layers, respectively. Contours represent AOT from dust sensitivity experiments for dust episodes 3-7.

As shown in Fig. 4a-b, very frequent dust emissions were simulated at the Taklimakan Desert area. These dust 

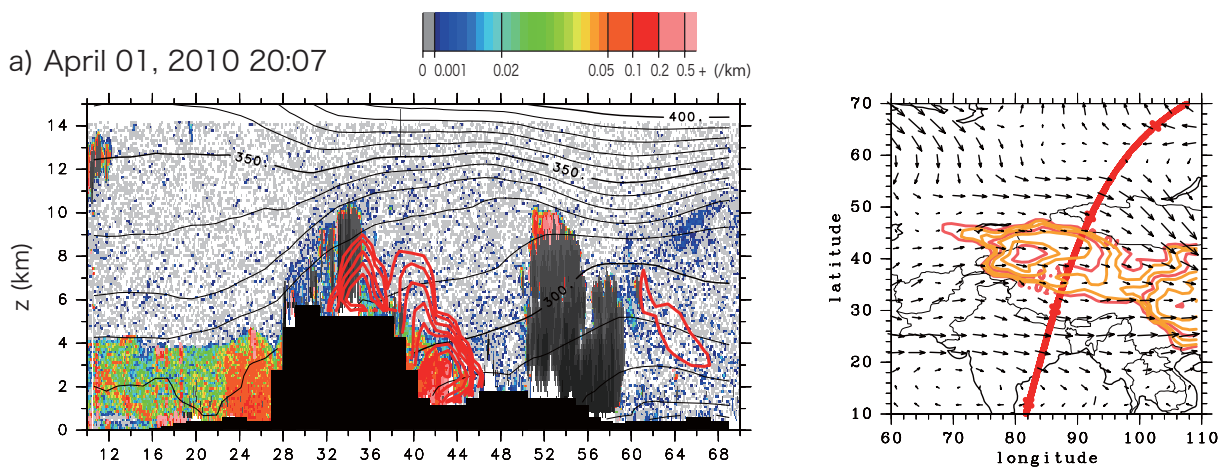

b) April 10, $201020: 02$
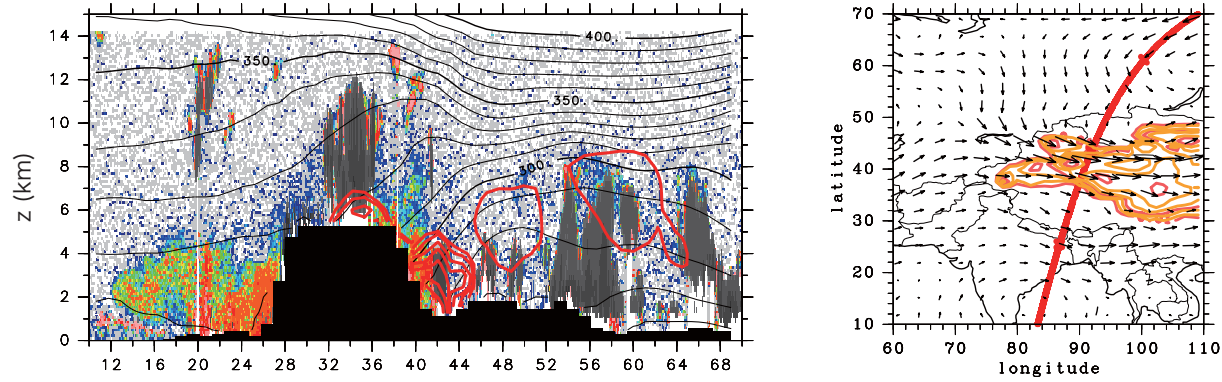

c) April 20, $201020: 40$
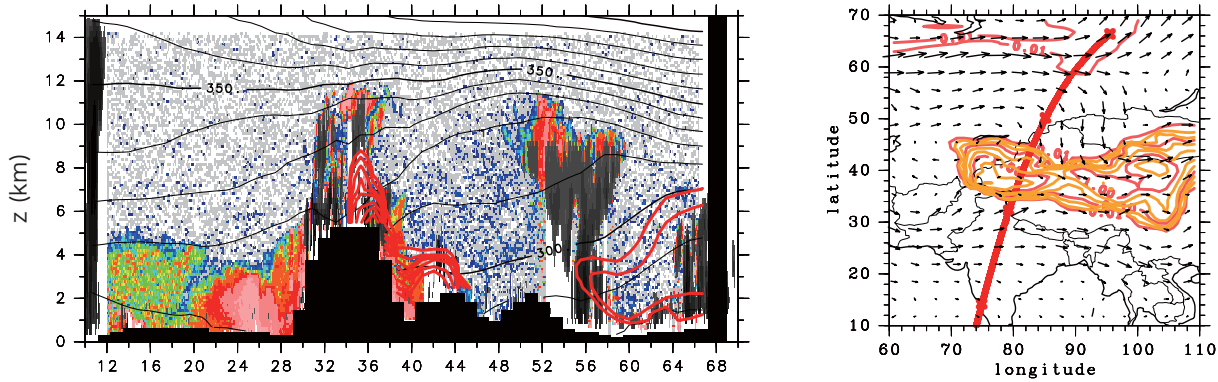

d) April 29, 2010 20:34
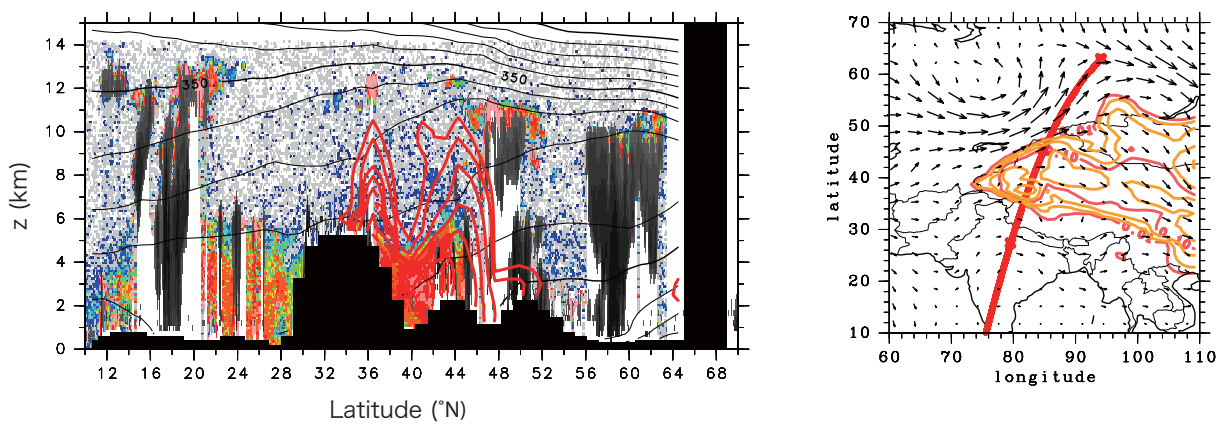

Fig. 5. The same as Fig. 2 but for dust source regions on (a) 1 April, (b) 10 April, (c) 20 April, and (d) 29 April.

episodes correlated reasonably well with MODIS Deep Blue AOT. Few cloud-free CALIOP orbits took place over the dust source region. We found that observations collected by CALIOP on 1, 10, 20, and 29 April were typical examples of dust generated during or shortly after a dust storm. Figure 5 shows the results over the dust source region, similar to Fig. 3. In all four cases, the dust extinction coeffi- cient exceeded $0.2 \mathrm{~km}^{-1}$. A thick dust layer filled the Tarim basin and some dust was transported onto the Tibetan plateau (heights up to $8 \mathrm{~km}$ ). These dust layers generally had potential temperatures between 290 and $310 \mathrm{~K}$, and their centers were about $300 \mathrm{~K}$. 

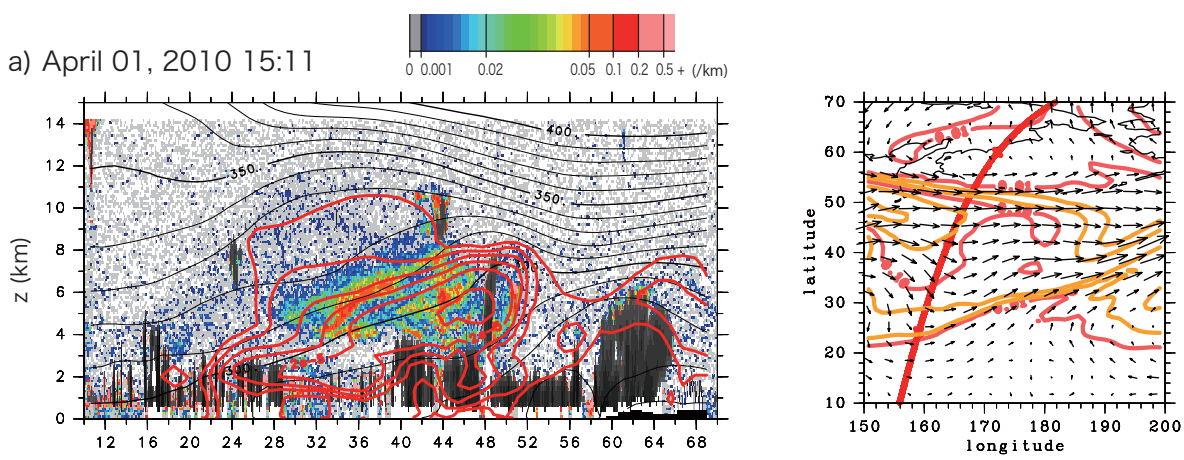

b) April 11, $201017: 28$
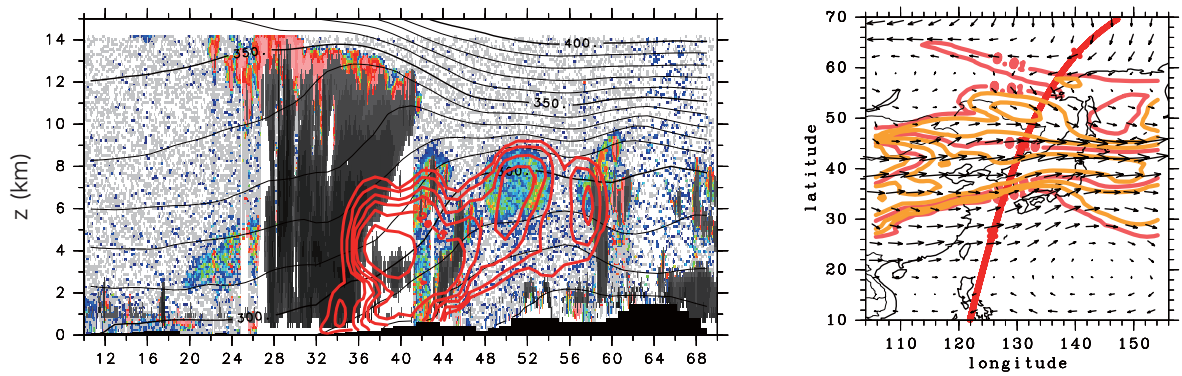

c) April 16, $201014: 29$
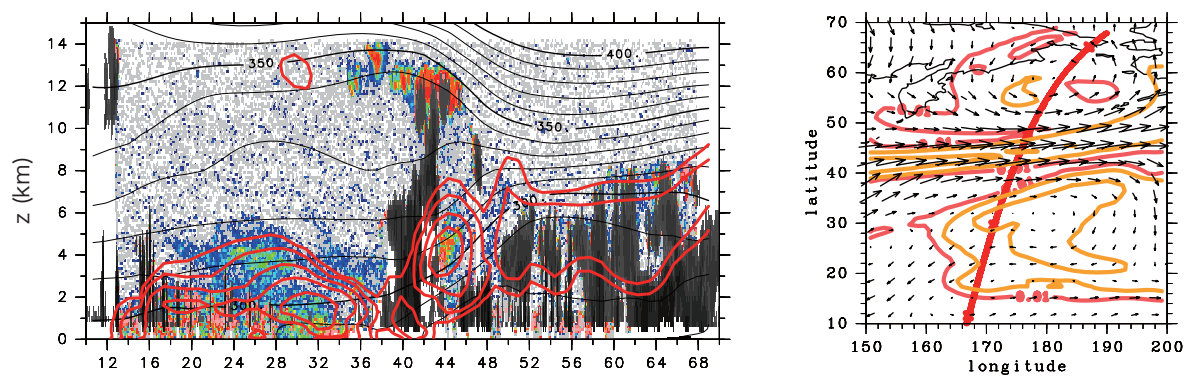

d) April 22, $201010: 34$
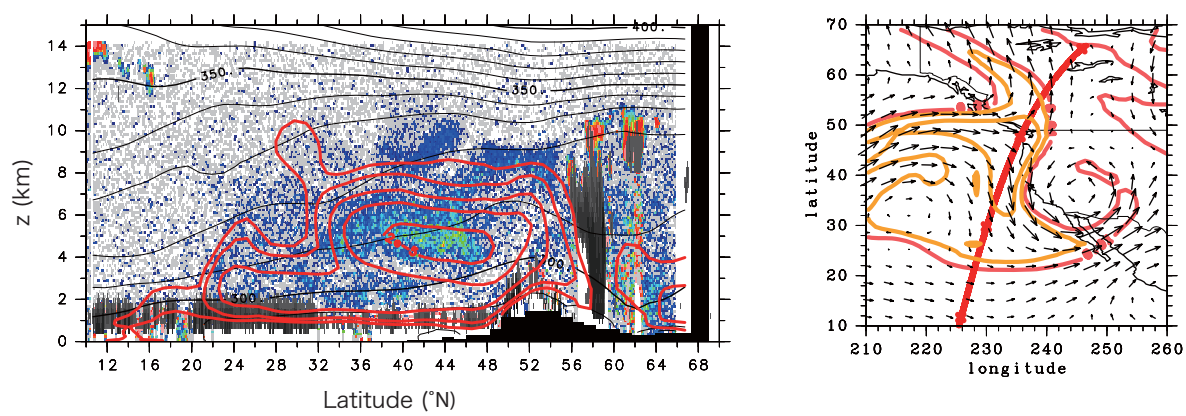

Fig. 6. The same as Fig. 2 but for downwind regions on (a) 1 April for the central/north Pacific Ocean, (b) 11 April for East Asia, (c) 16 April for the central/north Pacific, and (d) 22 April for the west coast of North America.

We also examined all nighttime CALIOP data from March-April 2010 from eastern Asia to northern America; the dust structure was very similar to that shown in Fig. 2. Figure 6 shows snapshots taken on 1 April (over the northwest Pacific), 11 April (over Korea and Japan), 16 April (over the central Pacific), and 22 April (over western North America). Model simulations were able to explain most of the dust layers observed by CALIOP quite well; the poten- tial temperature of $300 \mathrm{~K}$ was a key level and was consistent with Figs.2 and 5. In several cases, large dust plumes were transported to North America, and their horizontal/vertical dimensions are similar to those shown in Fig. 2. The dust layers observed by CALIOP (red bar) agreed well with the dust AOT shown in Fig. 4, confirming the frequent Asian dust transport to the central Pacific and finally to North America. 
Dust emission episodes 3, 5, and 7 were large, and we could easily track the dust transport as shown in the contours in Fig. 4. Our dust tracking, based on modeled AOT and CALIOP observations, demonstrated that Asian dust reached North America at least five times (episodes 3, 4, 5, 6, and 7) during April 2010, and sometimes dust from separate dust emission episodes mixed together over North America (e.g., episodes 5 and 6). Trans-Pacific dust transport occurred frequently, especially as shown in dust cloud 5, which branched into two paths (see Sect. 3.1); the northern path reached western North America on 15 April and the central region around 17 April.

\section{Conclusions}

Multiple large Asian dust plumes (2000-3000 km) arrived in North America in April 2010, occupying the full troposphere. We conducted an analysis based on space-borne lidar measurements and a global dust transport model and produced seven main findings. (1) In 2010, stronger-thanaverage winds that may have been the result of a large negative phase of the Arctic oscillation during the winter-spring of 2010 caused frequent large dust emissions in northwestern China (including the Taklimakan Desert). (2) A strong stable westerly moved from northwestern China to the central Pacific Ocean and frequently transported dust. (3) Dust transport height generally ranged from $2-10 \mathrm{~km}$. (4) Negative and positive pressure anomalies were observed over the eastern Pacific Ocean and northeastern America, respectively. The negative pressure anomaly split the main dust transport into two branches: one (the northern path) over the western US-northern Canada-central/eastern US and the other (the southern path) over the western-central/southern-eastern US (5) Dust along the northern path became trapped within a high-pressure system and was stagnant for a longer time before subsidence. (6) These complex conditions formed complex multiple layers of dust over North America. (7) The dust phenomena were well explained by the numerical model and captured by CALIOP measurements.

Acknowledgements. This work was partly supported by a Grantin-Aid for Scientific Research in Priority Areas "Western Pacific Air-Sea Interaction Study" (W-PASS) under Grant Nos. 18067005 and 21241003 from the Ministry of Education, Culture, Sports, Science and Technology (MEXT), Japan and by the Global Environment Research Fund, Ministry of Environment, Japan (C-091). CALIPSO data were obtained from the NASA Langley Research Center Atmospheric Sciences Data Center. The authors thank Y. Hagihara for CloudSAT data processing, C. Hsu and the MODIS Atmosphere Discipline Group for providing MODIS data, and D. Winker and the CALIPSO science team for providing CALIOP data.

Edited by: Q. Fu

\section{References}

Draxler, R. R. and Rolph, G. D.: HYSPLIT (HYbrid Single-Particle Lagrangian Integrated Trajectory) Model access via NOAA ARL READY website (http://ready.arl.noaa.gov/HYSPLIT.php), NOAA Air Resources Laboratory, Silver Spring, MD, 2010.

Eguchi, K., Uno, I., Yumimoto, K., Takemura, T., Shimizu, A., Sugimoto, N., and Liu, Z.: Trans-pacific dust transport: integrated analysis of NASA/CALIPSO and a global aerosol transport model, Atmos. Chem. Phys., 9, 3137-3145, doi:10.5194/acp-93137-2009, 2009.

Gong, S. L., Zhang, X. Y., Zhao, T. L., Zhang, X. B., Barrie, L. A., McKendry, I. G., and Zhao, I. S.: A simulated climatology of Asian dust and its trans-Pacific transport, Part II: Interannual variability and climate connections, J. Climate, 19, 104122, 2006.

Hsu, N., Tsay, S., King, M., and Herman, J.: Deep Blue retrievals of Asian aerosol properties during ACE-Asia, IEEE Trans. Geosci. Remote Sens., 44, 3180-3199, 2006.

Husar, R., Tratt, D. M., Schichtel, B. A., Falke, S. R., Li, F., Jaffe, D., Gassó, S., Gill, T., Laulainen, N. S., Lu, F., Reheis, M. C., Chun, Y., Westphal, D., Holben, B. N., Gueymard, C., McKendry, I., Kuring, N., Feldman, G. C., McClain, C., Frouin, R. J., Merrill, J., DuBois, D., Vignola, F., Murayama, T., Nickovic, S., Wilson, W. E., Sassen, K., Sugimoto, N., and Malm, W. C.: Asian dust events of April 1998, J. Geophys. Res., 106(D16), 18317-18330, doi:10.1029/2000JD900788, 2001.

Liang, Q., Jaeglé, L., and Wallace, J. M.: Meteorological indices for Asian outflow and transpacific transport on daily to interannual timescales, J. Geophys. Res., 110, D18308, doi:10.1029/2005JD005788, 2005.

Mao, R., Ho, C.-H., Shao, Y., Gong, D.-Y., and Kim, J.: Influence of Arctic oscillation on dust activity over northeast Asia, Atmos. Environ., 45, 326-337, 2011.

Shimizu, A., Sugimoto, N., Matsui, I., Arao, K., Uno, I., Murayama, T., Kagawa, N., Aoki, K., Uchiyama, A., and Yamazaki, A.: Continuous observations of Asian dust and other aerosols by polarization lidars in China and Japan during ACE-Asia, J. Geophys. Res., 109, D19S17, doi:10.1029/2002JD003253, 2004.

Su, L. and Toon, O. B.: Saharan and Asian dust: similarities and differences determined by CALIPSO, AERONET, and a coupled climate-aerosol microphysical model, Atmos. Chem. Phys., 11, 3263-3280, doi:10.5194/acp-11-3263-2011, 2011.

Takemura, T., Nozawa, T., Emori, S., Nakajima, T. Y., and Nakajima, T.: Simulation of climate response to aerosol direct and indirect effect with aerosol transport-radiation model, J. Geophys. Res., 110, D02202, doi:10.1029/2004JD005029, 2005.

Uno, I., Yumimoto, K., Shimizu, A., Hara, Y., Sugimoto, N., Wang, Z., Liu, Z., and Winker, D. M.: 3-D structure of Asian dust transport revealed by CALIPSO lidar and a 4DVAR dust model, Geophys. Res. Lett., 35, L06803, doi:10.1029/2007GL032329, 2008.

Uno, I., Eguchi, K., Yumimoto, K., Takemura, T., Shimizu, A., Uematsu, M., Liu, Z., Wang, Z., Hara, Y., and Sugimoto, N.: Asian dust transported one full circuit around the globe, Nat. Geosci., 2, 557-560, doi:10.1038/ngeo583, 2009.

VanCuren, R. and Cahill, T.: Asian aerosols in North America: Frequency and concentration of fine dust, J. Geophys. Res., 107(D24), 4804, doi:10.1029/2002JD002204, 2002.

Van den Dool, H., Huang, J., and Fan, Y.: Performance and analysis of the constructed analogue method applied to U.S. 
soil moisture over 1981-2001, J. Geophys. Res., 108, 8617, doi:10.1029/2002JD003114, 2003.

Winker, D. M., Hunt, W. H., and McGill, M. J.: Initial performance assessment of CALIOP, Geophys. Res. Lett., 34, L19803, doi:10.1029/2007GL030135, 2007.

Winker, D. M., Pelon, J., Coakley Jr., J. A., Ackerman, S. A., Charlson, R. J., Colarco, P. R., Flamant, P., Fu, Q., Hoff, R., Kittaka, C., Kubar, T. L., LeTreut, H., McCormick, M. P., Megie, G., Poole, L., Powell, K., Trepte, C., Vaughan, M. A., and Wielicki, B. A.: The CALIPSO mission: A global 3-D view of aerosols and clouds, B.. Am. Meteorol. Soc., 91, 1211-1229, doi:10.1175/2010BAMS3009.1, 2010.
Yumimoto, K., Eguchi, K., Uno, I., Takemura, T., Liu, Z., Shimizu, A., and Sugimoto, N.: An elevated large-scale dust veil from the Taklimakan Desert: Intercontinental transport and three-dimensional structure as captured by CALIPSO and regional and global models, Atmos. Chem. Phys., 9, 8545-8558, doi:10.5194/acp-9-8545-2009, 2009. 